Int. J. Electrochem. Sci., 11 (2016) 8530 - 8545

\title{
Electrochemical Impedance Spectroscopy Characteristic of Ti- 6Al-4V Alloy with and Without Welding under the Different Load Model
}

\author{
Yan Liu ${ }^{1}$, Shawei Tang ${ }^{1}$, Guangyi Liu ${ }^{1,2}$, Yue Sun ${ }^{1}, \mathrm{Jin} \mathrm{Hu}^{1, *}$ \\ ${ }^{1}$ School of Materials Science and Engineering, Harbin Institute of Technology, Harbin 150001, China \\ ${ }^{2}$ State Key Laboratory for Marine Corrosion and Protection, Luoyang Ship Material Research Institute \\ (LSMRI), Qingdao 266101, China \\ "E-mail: hujin@hit.edu.cn
}

doi: $10.20964 / 2016.10 .18$

Received: 31 May 2016 / Accepted: 29 July 2016 / Published: 6 September 2016

\begin{abstract}
Electrochemical impedance spectroscopy (EIS) measurements are performed on a Ti-6Al-4V alloy with and without welding. EIS measurements are always performed simultaneously on two identical specimens: one stressed with a slow strain rate tensile test or a constant load test and one free of stress test. A similar electrochemical characterization is exhibited on the alloys with and without welding during exposure in a LiCl-methanol solution. However, their corrosion mechanisms in the corrosion media are completely different. The difference in the surface states of the welded and non-welded alloy is responsible to the change of the corrosion mechanism. The welded alloy exhibit high susceptibility to corrosion and stress corrosion cracking. The applied stress promotes the corrosion process.
\end{abstract}

Keywords: Ti-6Al-4V alloy; Laser beam welding; Electrochemical impedance spectroscopy; SSRT

\section{$\underline{\text { FULL TEXT }}$}

(C) 2016 The Authors. Published by ESG (www.electrochemsci.org). This article is an open access article distributed under the terms and conditions of the Creative Commons Attribution license (http://creativecommons.org/licenses/by/4.0/). 